\title{
Quantitative Immunology of Immune Hemolytic Anemia
}

\author{
I. THE FIXATION OF C1 BY AUTOIMMUNE ANTIBODY \\ AND HETEROLOGOUS ANTI-IGG ANTIBODY
}

WeNDELL F. Rosse

From the Duke University Medical Center, Durham, North Carolina 27706

\begin{abstract}
A B S T R A C T The fixation of the first component of complement $(\mathrm{C} \overline{1})$ by rabbit and goat anti-IgG antibodies reacting with auto- or isoimmune antibodies attached to red cells has been investigated. Two molecules of the rabbit IgG anti-IgG were required to fix a single molecule of $C \overline{1}$, whereas only one molecule of goat IgM anti-IgG was required. The relationship between the number of auto- or isoimmune antibody molecules attached to the red cells and the amount of $C \overline{1}$ fixed by anti-IgG was determined by the concentration of antiIgG. A concentration of anti-IgG was found such that the number of molecules of $C \overline{1}$ fixed was directly proportional to the concentration of auto- or isoimmune antibody. By this method a sensitive, reproducible minimum estimate of the amount of cell-bound and serum antibody could be made.
\end{abstract}

\section{INTRODUCTION}

The factors involved in the destruction of red cells in patients with immune hemolytic anemia have been difficult to assess because of the difficulty in obtaining quantitative data about the immunological reactions which take place at the red cell surface. These reactions involve antibodies of different types, antigens of different specificities, and, in some instances but not others, the fixation of complement (1). Recently we have investigated the relationship of the type and quantity of the antibody to the fixation of the first component of complement in vitro and thus to the initiation of the complement sequence (2). Most autoimmune antibodies which react with the red cell at body temperature are IgG in type and require two molecules of antibody in a specific geometrical relationship for the fixation of a molecule of $C \overline{1}$. The antibodies which react with the red cell only at reduced temperature are usually IgM

Received for publication 20 July 1970 and in revised form 7 December 1970. (cold agglutinins) and require only one molecule of antibody to fix a molecule of $\mathrm{C} \overline{1}$. This difference in temperature of reaction and in ability to fix $\mathrm{C}^{\prime}$ probably determines differences in the mechanism of lysis of the cells.

Since the warm agglutinin antibodies are bound to the cell during its circulation, and since little or no complement may be fixed, the presence of antibody at the cell surface is probably the main determinant marking the cell for destruction. The relationship between the amount of antibody at the cell surface and its destruction has not been well studied, chiefly because the methods of determining the amount of bound antibody have been crude.

In recent years, methods of quantitating immune reactions have become available through increased knowledge of the complement system. Borsos and Rapp first quantitated immune reactions by measuring the amount of the first component of complement fixed by antibody-antigen reactions (3). We have applied this system to the study of the human antibodies and have found, as did Borsos and Rapp, that the amount of $C \overline{1}$ fixed depended upon the type of antibody as well as its concentration at the red cell surface (2). In this sytem, the relative amount of $\operatorname{IgM}$ antibody on the cell may be measured directly since a single antibody molecule is able to fix a molecule of $C \overline{1}$. However, the relative concentration of cell-bound IgG may not be directly measured since two molecules of antibody are needed to fix a molecule of $C \overline{1}$, leaving many single antibody molecules which do not fix $C \overline{1}$.

In the present paper, we present a method for the detection and quantitation of the amount of IgG antibody on the red cell surface using quantitative complement techniques and heterologous anti-immunoglobulin antisera. The complex relationship between the concentration of primary antibody, anti-antibody, and the amount of $C \overline{1}$ fixed are presented in order to derive 
a method for quantitating the direct and indirect antiglobulin test in patients with immune hemolytic anemia due to IgG antibody.

\section{METHODS}

\section{Patient material}

The antibodies used in this study were from patients found to have autoimmune hemolytic anemia by the presence of hemolytic anemia and a positive direct Coombs test due to the presence of IgG antibody on their red cells. A brief clinical summary is given in the second paper of this series (4).

Red cells. Blood was taken by aseptic venisection from patients and donors and was placed immediately in an equal volume of Alsever's solution made according to the formula given in reference 5 . At the time of use, the red cells were washed three times in Veronal-buffered saline and the concentration of the suspension was adjusted to contain 2.2 $\times 10^{8}$ red blood cells per $\mathrm{mm}^{3}$ according to the method given in reference 6.

Antibodies. Antibody-rich eluates were made from the red cells of patients with immune hemolytic anemia by either the method of Rubin (7) or of Landsteiner and Miller (8). When whole serum was used as a source of antibody, it was heated for $30 \mathrm{~min}$ at $56^{\circ} \mathrm{C}$ before use.

\section{Heterologous antibodies against human immunoglobulins-(anti-antibody)}

Rabbit anti-IgG was obtained by the injection of purified human IgG into rabbits, with Freund's adjuvant, or from the Ortho Pharmaceutical Corp., Raritan, N. J. $2 \mathrm{ml}$ of these antisera was fractionated on a Sephadex G-200 column. The anti$\mathrm{IgG}$ activity in each case was found in the peak containing IgG immunoglobulins.

Goat anti-IgG antiserum. Antiserum to purified human IgG immunoglobulin was prepared in goats. The antiserum was absorbed with type I and type II Bence Jones protein. On immunoelectrophoresis against whole human serum, a single arc due to precipitation with IgG globulin was seen.

$2 \mathrm{ml}$ of the goat anti-IgG antiserum was chromatographed on a column of Sephadex G-200. The anti-IgG activity was predominently in the first (IgM) peak. A small amount was found in the second peak containing IgG immunoglobulins.

\section{Buffers}

Veronal-buffered saline (VBS). An isotonic saline buffer, $\mathrm{pH} \mathrm{7.4,} \mathrm{was} \mathrm{made} \mathrm{according} \mathrm{to} \mathrm{the} \mathrm{formula} \mathrm{given} \mathrm{in} \mathrm{reference}$ 5. $\mathrm{Ca}^{++}$and $\mathrm{Mg}^{++}$were added to concentrations of 0.015 mole/liter and 0.005 mole/liter, respectively.

Sucrose. An isotonic solution of sucrose was made according to the formula given in reference 9 . When buffers of intermediate ionic strength were required, this buffer was mixed with appropriate amounts of VBS. The usual mixture was $60 \%$ isotonic sucrose and $40 \% \mathrm{VBS}$; this buffer has an ionic strength of 0.067 and will be referred to as VBS-sucrose buffer.

EDTA (ethylenediaminetetraacetate, disodium salt). An isotonic solution of $0.09 \mathrm{M}$ EDTA was made according to the formula given in reference 10 . When dilutions of this were required, they were made with VBS without added calcium and magnesium.

\section{Complement components}

$C \overline{1}$. The first component of complement was partially purified from guinea pig or human serum by the method of Borsos and Rapp (11). The solutions which were used contained $10^{12}-10^{13}$ effective molecules of complement by the hemolytic assay of Borsos and Rapp (11). These solutions contained no $\mathrm{C} 2$ or $\mathrm{C} 4$ as detected by hemolytic assay.

C2. The second component of complement was partially purified from guinea pig serum according to the method of Borsos, Rapp, and Cook (12). This method was slightly modified in that the $\mathrm{pH}$ of the CM-cellulose was brought to 4.8. All exchange resins were allowed to equilibrate with their buffers for at least $1 \mathrm{wk}$ before use. The solution that was obtained contained $10^{11}-10^{12}$ effective molecules of $\mathrm{C} 2$ by the hemolytic assay of Borsos and Rapp (13).

Sheep cells. Sheep cells were obtained fresh at weekly intervals and were collected and stored in an equal volume of Alsever's solution which had been made according to the formula given in reference 5 . At the time of use, the sheep cells were washed twice in $0.015 \mathrm{M}$ EDTA, and three times in VBS.

Antibody. Antibody to boiled sheep red cell stroma was made in rabbits according to the method of Mayer (5). This antibody was IgM in immunoglobulin type and had almost no agglutination properties.

$E A C 4$. Sensitized sheep red cells containing only the fourth component of complement (C4) were made according to the method of Borsos and Rapp (14). All procedures were performed stictly at $0^{\circ} \mathrm{C}$. in order to minimize the number of ineffective $\mathrm{C} 4$ sites.

$C$-EDTA. In order to provide the other components of complement (C3, C5-C9), guinea pig serum absorbed with sheep red cells was diluted 1 part in 50 in 0.015 м EDTA. Because of the chelation of the cations, calcium and magnesium, $\mathrm{C} \overline{1}$ and $\mathrm{C} 2$ present in the serum were not able to act in the complement sequence.

$C \overline{1}$ fixation and transfer test ( $\vec{C} \overrightarrow{1} f t$ test). The fixation and transfer test was performed according to the method of Borsos and Rapp (3), with modification of the first stage. Human red cells in standard suspension were sensitized with appropriate amounts of autoimmune ("primary") antibody. After washing with VBS-sucrose buffer, they were reacted with an appropriate concentration of heterologous antiserum containing anti-IgG antibodies. After being washed twice, the cells were then suspended in $0.3 \mathrm{ml}$ of partially purified guinea pig $C \overline{1}$ which had been absorbed twice with normal human red cells. After incubation for $30 \mathrm{~min}$ at $30^{\circ} \mathrm{C}$, the cells were suspended in VBS-sucrose buffer, centrifuged, and the pellet carefully transferred to a second tube. The cells were washed thrice more with VBS-sucrose buffer and were suspended in 9 $\mathrm{ml}$ of VBS buffer. The number of molecules of $C_{\overline{1}}$ contained in this solution was then determined by the method of Borsos and Rapp (11), and the number of molecules of $\mathrm{C}^{-}$fixed per red cell was calculated. The fixation of $C^{\overline{1}}$ by red cells alone, red cells and primary antibody, and red cells and anti-IgG was determined for each experiment when appropriate.

\section{RESULTS}

\section{The fixation of $\mathrm{Cl}$ by antibody with and without anti-IgG}

$0.1 \mathrm{ml}$ aliquots of a standard suspension of cells were sensitized with $0.1 \mathrm{ml}$ volumes of different dilutions of eluate from the cells of patient L. W. To one set of sensitized cells, $0.2 \mathrm{ml}$ of rabbit anti-IgG was added; to 
another, $0.2 \mathrm{ml}$ of goat anti-IgG, and to a third, $0.2 \mathrm{ml}$ of sucrose-VBS buffer. $C \overline{1}$ was added to all sets after incubation and the amount of $C \overline{1}$ fixed per cell was determined in the $C \overline{1}$ fixation and transfer test. The results are shown on Fig. 1. No $C \overline{1}$ ls fixed in the absence of anti-IgG. The maximal fixation of $C \overline{1}$ is at a $\frac{1}{4}$ dilution concentration of antibody L. W. with the rabbit antiIgG. Nearly maximal amounts of $C \overline{1}$ were fixed at $\frac{1}{16}$ dilution of antibody when the goat anti-IgG was used.

\section{The number of molecules of heterologous anti-IgG required to fix a molecule of $C \overline{1}$}

Human red cells were sensitized with a high concentration of autoimmune IgG antibody (primary antibody). Aliquots of these cells were reacted with graded concentrations of rabbit anti-IgG (an IgG antibody) or goat anti-IgG (an IgM antibody). The dose-response curves at limiting concentrations of anti-IgG differed for the two classes of anti-antibody. For the IgG rabbit antibody, the curve was parabolic when the relative concentration of anti-IgG was plotted against the number of molecules of Cî̀ fixed per sensitized cell. When the logarithm of the relative concentration of anti-IgG was plotted against the logarithm of the number of $C \overline{1}$ molecules fixed, a straight line resulted, the slope of which was 2.0. This indicates that two molecules of anti-IgG in juxtaposition were required for the fixation of a single molecule of $\mathrm{C} \overline{1}$ (15) (Fig. 2).

For the IgM goat anti-IgG antibody, the dose-response curve was linear at limited concentrations of anti-antibody. When the logarithm of the relative con-

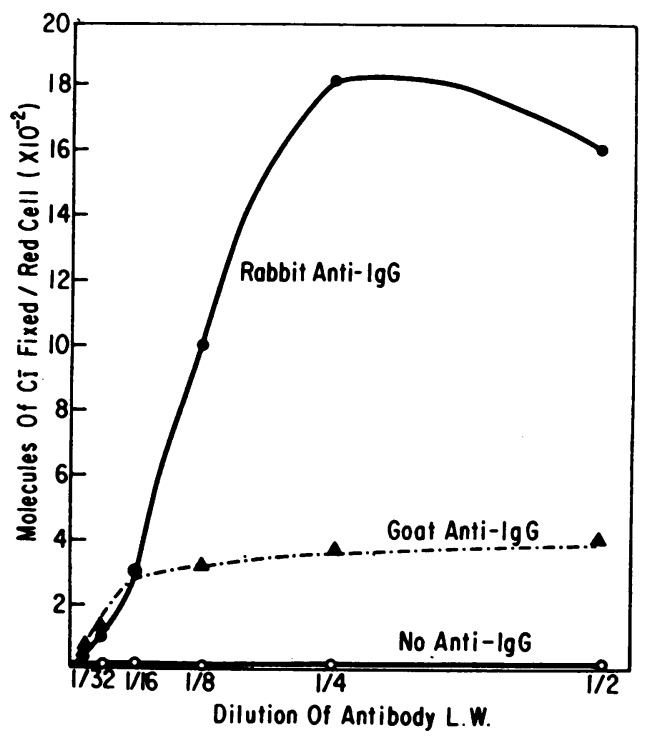

FIGURE 1 The fixation of $\mathrm{C}^{\overline{1}}$ by different concentrations of antibody $\mathrm{L}$. W. in the presence of $0.2 \mathrm{ml}$ of rabbit or goat anti-IgG antibody.

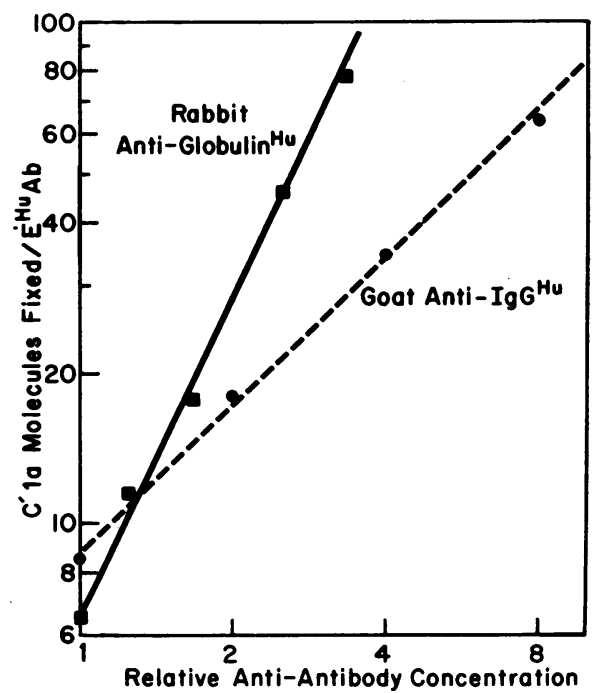

FIGURE 2 The fixation of $C \overline{1}$ by graded limiting concentrations of anti-IgG reacting with antibody $L$. W. present in high concentration on red cells. The logarithm of the relative antiIgG concentration is graphed against the logarithm of the number of molecules of $\bar{C} \overline{1}$ fixed per red cell.

centrations of anti-antibody was plotted against the logarithm of the number of molecules of $C \overline{1}$ fixed, the resulting line was straight and the slope of the line was 1 (Fig. 2). This indicates that a single molecule of this antibody, having reacted with the primary antibody, is capable of fixing a molecule of complement $(2,15)$.

When higher concentrations of anti-antibody were used, the dose-response curves became more complex. When goat anti-IgG was reacted with red cells sensitized with primary antibody L. W. diluted $\frac{1}{8}$ (heavy sensitization), the linear dose-response curve was seen between $0.0125 \mathrm{ml}$ and $0.1 \mathrm{ml}$ of the anti-IgG. Above this con-

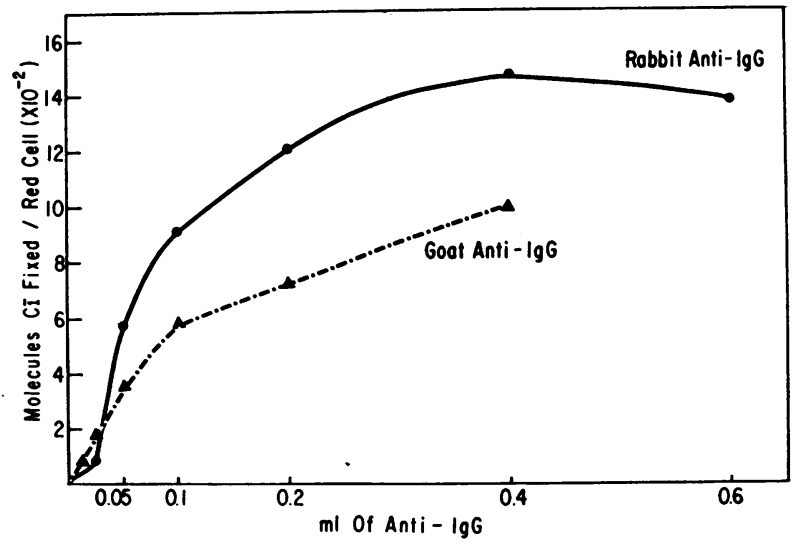

FIgURE 3 The fixation of $C \overline{1}$ by graded concentrations of goat and rabbit anit-IgG reacting with antibody $L$. W. present in high concentration on normal red cells. 


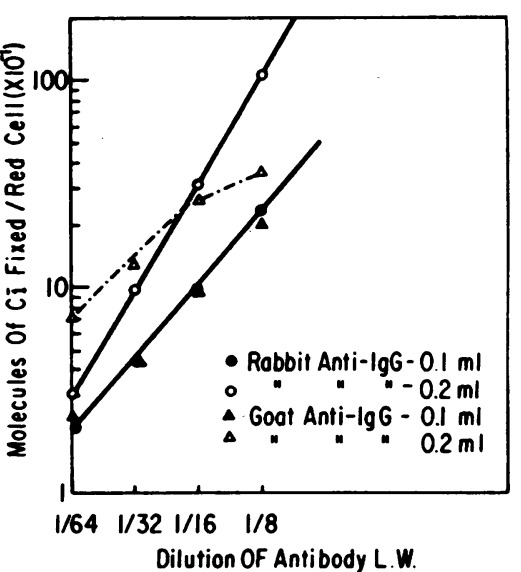

Figure 4 The fixation of $\mathrm{C} \overline{1}$ by graded concentrations of antibody $\mathrm{L}$. W. and two concentrations of goat and rabbit anti-IgG. The logarithm of the relative concentration of antibody L. W. is graphed against the logarithm of the number of molecules of $\mathrm{C}^{\overline{1}}$ fixed per red cell.

centration of the anti-antibody, the relationship was no longer linear (Fig. 3).

When varying amounts of rabbit anti-IgG were reacted with cells which had been heavily sensitized with primary antibody L. W. ( $\frac{1}{8}$ dilution), a sigmoidal curve was obtained (see Fig. 3). The initial parabolic portion has been discussed above. The maximum amount of $\mathrm{C} 1$ was fixed by $0.4 \mathrm{ml}$ of the anti-IgG. However, when a lower concentration of primary antibody was used to sensitize the cells (a $\frac{1}{32}$ dilution), the maximal amount of complement was fixed at a concentration of $0.1 \mathrm{ml}$ of anti-IgG, and further increases in its concentration did not increase the amount of $C \overline{1}$ fixed.

TABLE I

Slope of the Line Relating the Logarithm of the Concentration of Autoimmune or Isoimmune Antibody and the Logarithm of the Number of Molecules of $C^{\prime}$ Fixed at Different Concentrations of Rabbit IgG

\begin{tabular}{lccccc}
\hline & \multicolumn{5}{c}{ Concentration of anti-IgG } \\
\cline { 2 - 6 } Primary \\
\cline { 2 - 6 } & 0.05 & 0.1 & 0.2 & 0.4 & 0.6 \\
\hline L. W. & $0.7(2)^{*}$ & $1.0(4)$ & $1.6(2)$ & 1.4 & 1.0 \\
E. B. & & & $1.7(2)$ & & \\
J. S. & & & 1.7 & & \\
R. L. & & 1.1 & 1.9 & & \\
D. L. & & & 1.7 & & \\
Anti-D & & $1.0(2)$ & $1.3(3)$ & 1.2 & 1.0 \\
Anti-c & & $1.07(2)$ & $1.3(2)$ & & \\
Anti-C & & 1.05 & 1.7 & & \\
Anti-e & & 0.9 & 1.0 & & \\
Anti-E & & & $1.6(2)$ & \\
\end{tabular}

* Number of times test performed.

\section{The effect of anti-antibody concentration on dose-response curves of primary antibody}

The effect of different concentrations of anti-antibody on the amount of $C \overline{1}$ fixed by cells sensitized with graded amounts of primary antibody (L. W.) was demonstrated using both goat anti-IgG and rabbit anti-IgG. When the goat anti-IgG was used, the amount of $\mathrm{C}_{\overline{1}}$ fixed was proportional to the relative concentration of primary antibody used to sensitize the cells for all concentrations of the anti-IgG. The slope of the line relating the logarithm of the primary antibody concentration to the logarithm of the amount of $C \overline{1}$ fixed was about 1 regardless of the concentration of anti-antibody used (Fig. 4).

However, when rabbit anti-IgG was used, the shape of the dose-response curve, and hence the slope of the logarithmic plot of relative concentration of primary antibody used in sensitization against the amount of $C \overline{1}$ fixed by the cells depended upon the concentration of the anti-IgG (Fig. 4 and Table I). At limiting concentrations of anti-IgG $(0.05 \mathrm{ml})$, the slope of the doseresponse line was less than 1 . As the amount of anti-IgG was increased, the total amount of $\mathrm{C} \overline{1}$ fixed by a given dilution of primary antibody increased as did the slope of the dose-response curve; a maximum of both measurements was found at a concentration equivalent to $0.2 \mathrm{ml}$ of anti-IgG. At very high concentrations of antiIgG, both the total amount of $\mathrm{C} \overline{1}$ fixed by a given concentration of primary antibody and the slope of the logarithmic dose-response curve decreased.

TABLE II

Results of Repeated Measurements of IgG Antibody Attached to Cells Using Rabbit Anti-IgG and Cî1 Fixation

\begin{tabular}{lccrc}
\hline $\begin{array}{c}\text { Antibody } \\
\text { dilution }\end{array}$ & $\begin{array}{c}\text { Anti- } \\
\text { IgG }\end{array}$ & Cells & Date & $\begin{array}{c}\text { Molecules } \\
\text { Cíncell }\end{array}$ \\
\hline & $m l$ & & & \\
L. W., 1/8 & 0.2 & J. P. & $2-17-67$ & 1310 \\
& & & $2-20-67$ & 1210 \\
& & & $6-15-67$ & 1170 \\
& & & $10-11-67$ & 1060 \\
& & & $11-7-67$ & 1020 \\
\cline { 3 - 4 } L. W., 1/8 & & W. R. & $8-16-67$ & 870 \\
& & & $8-29-67$ & 750 \\
& & & $9-12-67$ & 620 \\
\cline { 3 - 4 } Anti-D & 0.2 & J. P. & $9-25-66$ & 5550 \\
& & & $9-27-66$ & 6380 \\
& & & $10-26-66$ & 3850 \\
& & & $10-27-66$ & 5282 \\
\hline
\end{tabular}




\section{Reproducibility of the results}

Reproducibility of the test results was investigated by repeating the test on different days, using a single concentration of autoimmune antibody, cells from the same donor, and a given concentration of anti-IgG. The results are shown on Table II.

The relationship of $C \overline{1}$ fixation and titers to agglutination. In two series of tubes, normal red blood cells in standard suspension $(0.1 \mathrm{ml})$ were incubated with 0.1 $\mathrm{ml}$ of graded dilutions of serum of patient R. A. (a patient with autoimmune hemolytic anemia and chronic lymphocytic leukemia). After washing, $0.1 \mathrm{ml}$ of rabbit anti-IgG was added and incubated for $30 \mathrm{~min}$. The cells were centrifuged and, in one series, were resuspended with gentle shaking and the amount of agglutination was microscopically estimated. In the other series, $C \overline{1}$ was added and the amount of $C \overline{1}$ fixed per cell was estimated. The results are shown in Fig. 5.

The effect of complement components on the red cell membrane upon the determination of antibody concentration. In order to determine if the presence of complement components on the cell surface altered the ability to detect IgG antibody, studies were performed in which the amount of antibody R. F. was determined when fresh serum was added to permit the addition of complement components and when the cells used were previously coated with complement components. In both instances, the amount of $\mathrm{C} \overline{1}$ fixed by anti-IgG was the same as when complement components were not present (see Table III).

\section{DISCUSSION}

The fixation of Cī by antibody appears to depend upon two characteristics of the antibody and its interaction with antigen. The immunoglobulin class of the antibody is important since it has been shown that a single mole-

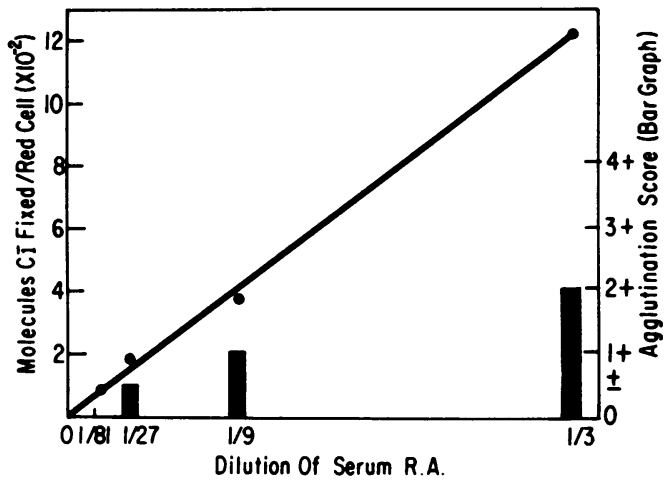

FIgURE 5 A comparison between the amount of $C \overline{1}$ fixed and the agglutination induced by a given concentration of rabbit anti-IgG reacting with cells sensitized with various concentrations of serum from a patient with immune hemolytic anemia.
TABLE III

Effect of Cell-Bound Complement Components on the Fixation and Detection of IgG

\begin{tabular}{|c|c|c|}
\hline \multirow[b]{2}{*}{ Conditions } & \multicolumn{2}{|c|}{$\begin{array}{l}\text { Molecules of } C \overline{1} \\
\text { fixed per cell }\end{array}$} \\
\hline & $\begin{array}{l}\text { By anti- } \\
\text { IgG }\end{array}$ & $\begin{array}{l}\text { By anti- } \\
\text { C 3* }\end{array}$ \\
\hline Serum R.F. $\ddagger$ E $\S$ & 610 & 0 \\
\hline $\begin{array}{l}\text { Serum R.F. }+ \\
\quad \text { Normal serum }+E \\
\quad \text { Normal serum }+E\end{array}$ & $\begin{array}{r}580 \\
0\end{array}$ & $\begin{array}{r}800 \\
50\end{array}$ \\
\hline $\begin{array}{l}\text { Serum R.F. + EC3\| } \\
\text { Normal serum }+ \text { EC3 }\end{array}$ & $\begin{array}{r}600 \\
0\end{array}$ & $\begin{array}{l}1300 \\
1450\end{array}$ \\
\hline
\end{tabular}

* Assay of cell-bound third component of complement (C3) by anti-C 3 and $\mathrm{C}^{\overline{1}}$ fixation and transfer as described by Logue and Rosse. In preparation.

$\ddagger$ Serum R. F. heated $56^{\circ} \mathrm{C}$ for $30 \mathrm{~min}$.

$\S \mathrm{E}$, normal cells.

|| EC3, normal red cell to which complement components have been added by reacting with cold agglutinin and fresh serum.

cule of IgM antibody from a variety of sources is capable of fixing a single molecule of $C \overline{1}$, whereas a "doublet" or two molecules of IgG antibody in some particular geometric relationship appear to be necessary for the fixation of a molecule of $\mathrm{C} \overline{1}(2,3)$. IgA antibodies apparently lack the site for the fixation of $C \overline{1}$ since none has been demonstrated to do so (16).

In addition to the immunoglobulin class of the antibody, the arrangement of the antigen sites on the cell surface also appear to be important in determining the fixation of $C \overline{1}$. Certain antibodies, especially those against antigens in the $\mathrm{Rh}$ system, are incapable of fixing $C \overline{1}$ even at very high concentrations of antibody. However, when IgG antibodies of several specificities in the $\mathrm{Rh}$ system are present on the cell at the same time, $C \overline{1}$ may be fixed, indicating that the lack of fixation of $C \overline{1}$ by antibodies of any given specificity is not an intrinsic property of the antibody (2). The absence of $C \overline{1}$ fixation is probably due to the distribution of the antigen sites such that doublet formation cannot occur.

The quantitation of antibody on the cell surface by its ability to fix $C \overline{1}$ is simple for antibodies of the IgM class which react with antigens present in large numbers on the red cell surface. We have shown that cold agglutinins may be easily measured on the surface of red cells since there is a direct relationship between the amount of cold agglutinin present and the amoumt of $C \overline{1}$ fixed $(2,17)$. However, quantitation of $\operatorname{IgG}$ antibodies by this method is very much more complex since many isoor autoimmune antibodies do not fix $\mathrm{C} \overline{1}$ at all and other antibodies only at a very high concentration of antibody. It is for this reason that we have investigated the 
quantitation of cell-bound IgG antibodies with the use of heterologous anti-IgG antibodies and the $C \overline{1}$ fixation and transfer test.

The fixation of $\mathrm{C} \overline{1}$ by anti-antibody reacting with antibody attached to the red cell surface appear to have the same requirements as the fixation of $C \overline{1}$ by antibody reacting directly with the red cell. From the present studies, it is apparent that a single molecule of $\operatorname{IgM}$ anti-IgG reacting with an IgG primary antibody molecule is sufficient for the fixation of a molecule of $C \overline{1}$. Thus, for a given amount of primary antibody the relationship between the amount of IgM anti-IgG present and the amount of $\mathrm{C} \overline{1}$ fixed is always linear. On the other hand, two molecules of $\mathrm{IgG}$ anti-IgG, reacting with cell-bound antibody, are necessary for the fixation of a molecule of $C \overline{1}$ since the slope of the dose-response line was 2 when the concentration of IgG anti-IgG is varied but remains limited. This result implies that the $\mathrm{C} \overline{1}$-fixing site of the IgG anti-IgG antibody cannot interact with the $\mathrm{C} \overline{\mathbf{1}}$-fixing site of the primary IgG antibody to form a doublet. If this were the case, the amount of $\mathrm{C} \overline{1}$ fixed would be directly proportional to the amount of IgG anti-IgG present and the slope of the dose-response curve on log-log plot would be 1 .

If the antiglobulin- $C \overline{1}$ fixation system is to be of value for the estimation of the amount of autoimmune or isoimmune (primary) antibody attached to red cells, the dose-response relationship between the amount of primary antibody and the amount of $C \overline{1}$ fixed must be established. This relationship is simple in the case of the goat IgM anti-IgG since the amount of $C \overline{1}$ fixed is proportional to the relative concentration of primary antibody, regardless of the concentration of anti-IgG present. As the concentration of anti-IgG was increased, more $\mathrm{C} \overline{1}$ was fixed at all concentrations of primary antibody. However, the concentration of antiIgG in this antiserum was limiting since a maximum fixation of $C \overline{1}$ was not reached, even with high concentrations of the antiserum.

Because two molecues of the IgG anti-IgG are required for the fixation of a molecule of $C \overline{1}$, the relationship between primary antibody concentration and the amount of $C \overline{1}$ varied with the concentration of antiIgG. Theoretically, the two anti-IgG molecules forming the $\mathrm{C} \overline{1}$-fixing doublet may be situated on a single primary antibody molecule (a "unit" doublet) or on adjacent primary antibody molecules (an "adjacent" doublet).

When the concentration of anti-IgG is very low, the number of doublets formed does not vary directly with increases in the amount of primary antibody attached. As more primary antibody is added to the cell, more potential sites are present for the random distribution of the limited number of anti-IgG molecules. Therefore, the chances of two molecules of anti-IgG forming a doublet are diminished. This is reflected in the fact that the logarithmic plot of the slope of the dose-response curve relating relative primary antibody concentration to $\mathrm{C} \overline{1}$ fixed when $0.05 \mathrm{ml}$ of anti-IgG is present is less than 1 .

If all doublets were "unit" doublet, the amount of $\mathrm{C} \overline{1}$ fixed would be directly proportional to the concentration of primary antibody and the slope of the logarithmic plot of the dose-response curve would be 1 . If all doublets fixing $C \overline{1}$ were "adjacent" doublets, then the slope of the logarithmic plot of the relative concentration of primary antibody to the amount of $C \overline{1}$ fixed would equal 2 . In the present experiments, as the amount of anti-IgG is increased, the slope of the doseresponse curve reaches a maximum approaching 2, suggesting that both unit and adjacent doublets were formed. The proportion of "adjacent" doublets, as measured by the degree to which the slope approaches 2 , is apparently somewhat less when $\mathrm{Rh}$ antibodies are used. This may relate to the fact that the antigen sites for the $\mathrm{Rh}$ antigens are probably sparser than for most other antibodies; therefore, there would be less chance of adjacent doublets forming with these antibodies. At very high concentrations of anti-IgG, the relationship between the concentration of primary antibody and $C \overline{1}$ fixation is difficult to explain.

In order for the measurement of $\mathrm{C} \overline{1}$ fixation to be of value in the estimation of antibody coating of cells, the relationship between the amount of antibody on the cell and the amount of $C \overline{1}$ fixed must be linear (i.e. the slope of the logarithmic plot of the dose-response curve must equal 1.0). This condition obtains when $0.1 \mathrm{ml}$ of IgG anti-IgG is used. It is not apparent from the data whether this relationship is due to the formation of unit doublets only.

Constantoukalis, Costea, Schwartz, and Dameshek (18) have suggested that up to seven anti-IgG molecules may react with a single IgG molecule. If this is so, then it is theoretically possible to have more than one "unit" doublet per IgG molecule. That condition, if it exists, does not alter the validity of the proportionality relationship between the amount of primary antibody present and the amount of $\mathrm{C} \overline{1}$ fixed at an appropriate concentration of anti-IgG.

The efficiency of this antiglobulin system in the detection of IgG antibody is difficult to assess. Using a similar technique, Borsos, Colten, Spalter, Rogentine, and Rapp estimated that $60-100 \%$ of $\operatorname{IgG}$ molecules were detected in certain instances and as low as $5 \%$ in other instances (19). However, these investigators did not include data concerning the effect of anti-antibody concentration on the relationship between primary antibody and the fixation of $C \overline{1}$. The present data show that by the appropriate adjustment of this concentration of anti-IgG, a minimal but proportional estimate of the num- 
ber of IgG antibody molecules at the surface may be obtained. Clearly many antibody molecules may go undetected but valid conclusions may be drawn from these relative estimates.

The advantages of this method of measuring IgG antibody on the red cell are the precision, reproducibility, and ease with which the test can be performed. Its usefulness in following the course of patients with immune hemolytic anemia will be demonstrated in a subsequent paper (4).

\section{ACKNOWLEDGMENTS}

This work was supported in part by NIH Grant 5R01-CA10267. Dr. Rosse is the recipient of Research Career Development Award 5 K04 CA38862. Hospitalization of patients was carried out on the Clinical Research Unit, Duke University Medical Center Grant MO1-FR-30.

\section{REFERENCES}

1. Dacie, J. V. 1961. The Haemolytic Anaemias. Grune \& Stratton Inc., New York. Part 2.

2. Rosse, W. F. 1968. Fixation of the first component of complement $\left(\mathrm{C}^{\prime} 1 \mathrm{a}\right)$ by human antibodies. J. Clin. Invest. 47 : 2430.

3. Borsos, T., and H. J. Rapp. 1965. Hemolysin titration based on the fixation of the activated first component of complement: evidence that one molecule of hemolysin suffices to sensitize an erythrocyte. J. Immunol. 95: 559.

4. Rosse, W. F. 1971. Quantitative immunology of immune hemolytic anemia. II. The relationship of cell-bound antibody to hemolysis and the effect of treatment. J. Clin. Invest. 50 : 734.

5. Mayer, M. M. 1961. Complement and complement fixation. In Experimental Immunochemistry. E. A. Kabat and M. M. Mayer, editors. Charles C Thomas, Springfield. 2nd edition. 133.

6. Rosse, W. F., and J. V. Dacie. 1966. Immune lysis of normal human and paroxysmal nocturnal hemoglobinuria (PNH) red blood cells. I. The sensitivity of PNH red cells to lysis by complement and specific antibody. $J$. Clin. Invest. 45 : 736.
7. Rubin, H. 1963. Antibody elution from red blood cells. J. Clin. Pathol. 16: 70.

8. Landsteiner, K., and C. P. Miller. 1925. Serological studies on the blood of primates. II. The blood groups in the anthropoid apes. J. Exp. Med. $42: 853$.

9. Rapp, H. J., and T. Borsos. 1963. Effects of low ionic strength on immune hemolysis. J. Immunol. $91: 826$.

10. Frank, M. M., H. J. Rapp, and T. Borsos: 1964. Studies on the terminal steps of immune hemolysis. I. Inhibition by trisodium ethylenediaminetetraacetate (EDTA). J. Immunol. 93 : 409.

11. Borsos, T., and H. J. Rapp. 1963. Chromatographic separation of the first component of complement and its assay on a molecular basis. J. Immunol. $91: 851$.

12. Borsos, T., H. J. Rapp, and C. T. Cook. 1961. Studies on the second component of complement. III. Separation of the second component from guinea pig serum by chromatography on cellulose derivatives. J. Immunol. 87: 330 .

13. Borsos, T., H. J. Rapp, and M. M. Mayer. 1961. Studies on the second component of complement. I. The reaction between $E^{\prime} C^{\prime} 1,4$ and $C^{\prime} 2$ : evidence on the single site mechanism of immune hemolysis and determination of $\mathrm{C}^{\prime} 2$ on a molecular basis. J. Immunol. $87: 310$.

14. Borsos, T., and H. J. Rapp. 1967. Immune hemolysis: a simplified method for the preparation of EAC'4 with guinea pig or with human complement. J. Immunol. 99: 263.

15. Borsos, T., and H. J. Rapp. 1965. Complement fixation on cell surfaces by $19 \mathrm{~S}$ and $7 \mathrm{~S}$ antibodies. Science (Washington). 150: 505 .

16. Ishizaka, T., K. Ishizaka, T. Borsos, and H. J. Rapp. 1966. C'1 fixation by human isoagglutinins: fixation of $\mathrm{C}^{\prime} 1$ by $\gamma \mathrm{G}$ and $\gamma \mathrm{M}$ but not by $\gamma \mathrm{A}$ antibody. J. Immunol. 97: 716.

17. Rosse, W. F., and J. B. Sherwood. 1970. Cold-reacting antibodies: differences in the reaction of anti-I antibodies with adult and cord red blood cells. Blood. 36: 28 .

18. Constantoulakis, M., N. Costea, R. S. Schwartz, and W. Dameshek. 1963. Quantitative studies of the effect of red-blood-cell sensitization on in vivo hemolysis. J. Clin. Invest. 42: 1790 .

19. Borsos, T., H. R. Colten, J. S. Spalter, N. Rogentine, and H. J. Rapp. 1968. The C'1a fixation and transfer test: examples of its applicability to the detection and enumer-. ation of antigens and antibodies at cell surfaces. $J$. Immunol. 101 : 392 . 